\title{
O intangível na produção do cuidado: o exercício da inteligência prática em uma enfermaria oncológica
}

\author{
The intangible in the production of care: the exercise of practical \\ intelligence in an oncology ward
}

Maria Liana Gesteira Fonseca (https://orcid.org/0000-0001-7372-012X) ${ }^{1}$

Marilene de Castilho Sá (https://orcid.org/0000-0002-8315-2979) ${ }^{2}$

${ }^{1}$ Instituto Nacional do Câncer. R. Marquês de Pombal $125 / 12^{\circ}$, Centro. 20230-240 Rio de Janeiro RJ Brasil.

liana.fonseca1@gmail.com

${ }^{2}$ Escola Nacional de Saúde Pública Sergio Arouca,

Fiocruz. Rio de Janeiro RJ Brasil.

\begin{abstract}
This article brings the results of a research of which main goal was to investigate the use of practical intelligence by an oncology nurse team in an oncological ward, in a hospital in the city of Rio de Janeiro, Brazil. We assume that, in spite of the suffering inherent to health care work, it can have a creative and potent dimension in the exercise of care, even in the presence of the challenges faced by the precarious working conditions, the growing demand of patients and the demands of productivity. Participant observation, in-depth interviews and group interviews were carried out with a selected nursing staff. We observed two main forms of practical intelligence manifestations. The first is the exercise of speaking and listening. The second, as an exercise in the production of comfort. Such forms of practical intelligence interpenetrate and cannot be captured by numbers, indicators, and methods of performance evaluation. They are invisible to instruments that do not go through the word of the workers. We conclude that it is necessary to create collective spaces in health organizations where managers and workers can express and dialogue on such issues, socially validating this know-how and those workers'experiences.
\end{abstract}

Key words Work, Work psychodynamics, Oncology nursing, Work phycology, Nursing care
Resumo Este artigo resulta de uma pesquisa cujo objeto é o saber-fazer dos trabalhadores de enfermagem. O objetivo principal foi investigar os usos da inteligência prática, em uma equipe de enfermagem de uma enfermaria oncológica no Rio de Janeiro. Partimos do pressuposto de que, a despeito do sofrimento inerente ao trabalho em saúde, este pode conter uma dimensão criativa e potente no exercício do cuidar, mesmo diante dos desafios colocados pelas precárias condições de trabalho, pela demanda crescente de pacientes e pelas exigências de produtividade. Foram realizadas observação participante, entrevistas em profundidade e entrevistas em grupo com trabalhadores da enfermaria selecionada. Observamos duas principais formas de manifestação da inteligência prática. A primeira, como exercício da palavra e da escuta. A segunda, como exercício da produção de conforto. Tais formas de inteligência prática se interpenetram e não são passiveis de captura por números, indicadores e métodos de avaliação do desempenho. São invisiveis para instrumentos que não passem pela palavra dos trabalhadores. Conclui-se pela necessidade de criação de espaços coletivos em que gestores e trabalhadores possam expressar e validar socialmente o saber-fazer e as experiências dos trabalhadores.

Palavras-chave Psicodinâmica do trabalho, Enfermagem oncológica, Psicologia do trabalho, Cuidados de enfermagem 


\section{Introdução}

O presente artigo tem origem em parte dos resultados de uma pesquisa realizada em uma enfermaria oncológica em um hospital do Rio de Janeiro $^{1}$. A pesquisa teve como objeto o uso da inteligência prática ${ }^{2,3}$, do saber-fazer dos trabalhadores de enfermagem, considerando suas estratégias de enfrentamento do sofrimento no trabalho, incluindo sua relação com os pacientes oncológicos e seus familiares. Tem como base teórica, principalmente, a Psicodinâmica do Trabalho (PDT).

Trabalhamos com a hipótese de que, apesar do imenso desafio do trabalho de cuidado e sua dimensão patogênica, há também uma dimensão criativa e potente no exercício do cuidar, a despeito dos desafios do cotidiano de trabalho. O saber-fazer do cuidado, chamado, em uma das suas dimensões, de saber-fazer discreto por Pascale Molinier ${ }^{4}$, tem uma dimensão invisível. Se, por um lado, é necessário que seja discreto para que se efetive como cuidado na relação e no vínculo entre trabalhador de saúde e paciente - em pequenos, porém fundamentais, gestos e atitudes do cotidiano na relação de cuidado - por outro, tal característica o torna impossível de captura pelos métodos tradicionais de gestão.

A invisibilidade deste tipo de saber se torna uma questão a passagem do sofrimento ao prazer no trabalho, de acordo com Psicodinâmica do Trabalho - referencial teórico deste trabalho.

Para a Psicodinâmica do Trabalho é justamente a dinâmica do reconhecimento que opera a passagem do sofrimento ao prazer no trabalho. Isso acontece quando é oferecida uma retribuição de natureza simbólica à contribuição singular do trabalhador. Esta retribuição é o reconhecimento. Portanto, a dimensão invisível dos trabalhos de cuidado faz justamente com que seja necessário um olhar diferenciado para este tipo de trabalho, na medida em que o que mais tem valor - na relação trabalhadora/trabalhador/paciente - é que menos se về.

Isto quer dizer também que, apesar de possíveis formas de organizações do trabalho potencialmente adoecedoras - porque não permitem que o trabalhador possa contribuir com ajustes no modo de realização do trabalho - há também o exercício da criatividade e de modos próprios de operar no saber-fazer da enfermagem quando no encontro com o usuário. Este saber-fazer é chamado por Cristhope Dejours de Inteligência Prática ou Inteligência Astuciosa ou Inteligência Criativa $^{2,3}$.
Dejours, baseado no conceito de Métis, dos gregos - do qual derivam as palavras metier, meticuloso - chamou essa inteligência de Inteligência Prática. Para Dejours, a inteligência prática é produzida no exercício do trabalho. É o exercício do trabalho e o confronto com o real que mobilizam a formação dessa inteligência tanto no nível individual, quanto no nível coletivo: "É o trabalho que produz a inteligência (prática) e não a inteligência que produz o trabalho"3.

Uma das principais fontes de sofrimento no trabalho é o entrave ao uso dessa inteligência. De onde podemos concluir que uma possível fonte de prazer seria o contrário, o livre exercício dessa inteligência como forma de contribuir com a organização do trabalho:

No lado oposto, o prazer está no encontro do trabalho, ao se descobrir que é precisamente quando a utilização dessa inteligência não é contrariada ou combatida, mas, ainda, quando se reconhece a contribuição fundamental que ela representa para a organização do trabalho. E esse prazer é de grande importância para a saúde plena, pois inscreve a relação do trabalho como mediadora da realização de si mesmo e da construção da identidade. É a condição necessária para tornar válido o aforismo segundo o qual "o trabalho é a saúde?.

A possibilidade de ter sua contribuição singular reconhecida, dentro da organização do trabalho, seja pelos pares - aquilo que Dejours chamou de reconhecimento de estética - seja pelas hierarquias - aquilo que Dejours chamou de reconhecimento de utilidade - produz o que o autor chamou de dinâmica do reconhecimento.

A inteligência prática não é equivalente aos requisitos cognitivos e uma de suas primeiras características é ser enraizada no corpo. No entanto, quando Dejours faz essa afirmativa, está se referindo a uma concepção específica de corpo. O autor não se refere ao mesmo corpo dos biólogos, mas a um segundo corpo, aquele que experimenta o mundo afetivamente, o corpo que é habitado, o corpo investido na relação com o outro ${ }^{3}$.

Dejours afirma também a experiência subjetiva do sofrimento como algo que é registrado no corpo:

[...] Não existe sofrimento sem um corpo para experimentá-lo. De fato, a inteligência no trabalho nunca é redutivel a uma subjetividade que sobrepuja o sujeito. A subjetividade só se experimenta na singularidade irredutivel de uma encarnação, de um corpo particular e de uma corporeidade absolutamente única ${ }^{3}$.

Assim, a métis ou a Inteligência Prática são parte essencial também do trabalho em saúde 
e, principalmente, do trabalho da enfermagem, visto que nesse ofício, geralmente, há um grande hiato entre o trabalho prescrito e o trabalho real. Tal hiato se configura como uma enorme fenda, por onde o trabalhador pode contribuir, mas que também lhe pode ser fonte de sofrimento, na medida em que sua formação garante prioritariamente os aspectos técnicos, teóricos e científicos. As dimensões relacionais, sumamente exigidas no cotidiano de trabalho dessa categoria, geralmente não são fonte de investimento prioritário nas suas formações.

Portanto, trabalhamos com a hipótese, nesta pesquisa, de que, além do sofrimento advindo da relação com o paciente oncológico, com as dores e desafios da atenção oncológica, há também uma dimensão de construção de saberes tácitos, fundamentais para o exercício do ofício de enfermagem, que acontece na relação de trabalhadoras e trabalhadores, na condição de sujeitos, com o exercício de seu trabalho.

\section{Estratégias de pesquisa}

Além do referencial teórico da psicodinâmica do trabalho, a pesquisa se apoiou, metodologicamente, na abordagem clínica psicossociológica, que enfoca a questão da relação entre pesquisa e ação ou entre teoria e prática não somente como produção de conhecimento. Essa abordagem, de certa forma, rompe com os princípios do positivismo científico, na medida em que considera que a pesquisa e o ato de intervenção são indissociáveis, quando se trata de lidar com grupos de sujeitos, comunidades ou organizações que carregam, ainda que implicitamente, alguma demanda relacionada a seus estados de sofrimento. Trata-se de uma abordagem que confere centralidade à produção de sentido e ao sofrimento dos sujeitos nos grupos e organizações.

As estratégias de pesquisa utilizadas foram a observação participante, as entrevistas em profundidade e duas entrevistas em grupo, realizadas com trabalhadores de uma mesma enfermaria oncológica, selecionada por ser considerada pelos gestores do hospital como o setor onde se verificava maior sofrimento entre os trabalhadores.

As observações participantes foram realizadas entre setembro de dois mil e doze e dezembro do mesmo ano, duas vezes por semana. Havia três equipes de plantões diurnos, com funcionamento de escala de doze por sessenta horas com complementações. Nesse período de pouco mais de três meses foi possível observar e estabelecer uma relação com as três equipes de plantão diurno. $\mathrm{O}$ plantão noturno não foi incluído por trazer elementos como o trabalho em turno, a diversidade de vínculos e outras questões que o trabalho de pesquisa não teria condições de abarcar.

Os elementos que foram o objeto das observações participantes foram os seguintes: relação da equipe de enfermagem com a organização do trabalho, tal como divisão do trabalho, tarefas prescritas, organização do tempo; relação com as demais categorias profissionais; relação com pacientes e seus familiares e reações diante de eventos não planejados no cotidiano de trabalho.

Para as entrevistas individuais em profundidade foram convidados todos os técnicos dos plantões diurnos, que somavam quinze, uma enfermeira diarista e três enfermeiras plantonistas também do turno diurno. Deste total de dezenove trabalhadores, quatorze concederam entrevistas em profundidade. Outros se limitaram a conversar nos espaços informais.

Para tais entrevistas foram usados elementos e temas que emergiram durante as observações participantes, que iam sendo inseridos na medida em que o trabalhador respondia a primeira pergunta, que era um pedido para falar livremente a respeito do próprio trabalho.

Ao todo, foram realizadas quatorze entrevistas em profundidade, sendo quatro com enfermeiras, nove com técnicas e uma com um técnico de enfermagem. O processo de realização das entrevistas durou dois meses, tendo começado em janeiro de dois mil e treze e terminado em março do mesmo ano. O longo período dedicado à realização das entrevistas individuais se deveu à preocupação com aguardar o momento mais oportuno para que cada trabalhador pudesse conceder sua entrevista, no tempo e duração que julgasse apropriado e se sentisse confortável.

Para Giust ${ }^{6}$, a entrevista, dentro da abordagem clínica de pesquisa: (...) é um dispositivo privilegiado para que os indivíduos e os grupos apreendam concretamente o modo como vivem, se submetem ou transformam as organizações nas quais eles inscrevem o seu acto, seja profissional ou não.

Os temas centrais que balizaram as entrevistas individuais em profundidade foram os seguintes: rotinas, tarefas, atribuições; o cotidiano de trabalho; o enfrentamento das dificuldades; sentimentos a respeito da equipe, dos pacientes e dos familiares; sentimentos a respeito do hospital e do setor.

As entrevistas em grupo tiveram a função de propiciar elaboração coletiva a respeito das questões emergentes que haviam surgido durante a observação participante e durante as entrevistas 
individuais. Tais questões faziam parte do cotidiano de trabalho da equipe de enfermagem e de seus sentimentos a respeito do trabalho. Sendo assim, por meio das entrevistas em grupo, a pesquisa se propôs a favorecer também a construção de sentido acerca das experiências do cotidiano de trabalho.

Para Giust ${ }^{6}$, as entrevistas permitem a exploração e elaboração das atitudes, assim como alargam as possibilidades de escuta e análise das situações. A autora observa que, na perspectiva da abordagem clínica psicossociológica de pesquisa, a entrevista é também um momento de intervenção:

(...) a entrevista, para o psicossociólogo, não se resume à condução da entrevista clínica [...] A entrevista psicossociológica é um dispositivo destinado a ouvir um pedido social (formulado ou informulado) para que haja uma abordagem da queixa, à doença, às situações de crise ${ }^{6}$.

As entrevistas em grupo foram organizadas de acordo com as categorias emergentes que surgiram nas etapas anteriores da pesquisa. A totalidade da equipe de enfermagem foi dividida em dois grupos para debater os temas que surgiram ao longo do trabalho de campo.

$\mathrm{O}$ projeto de pesquisa foi submetido à avaliação do Comitê de Ética em Pesquisa da ENSP/ Fiocruz e ao Comitê de Ética da instituição co -participante via Plataforma Brasil. Foi aprovado, definitivamente, depois de pequenas correções nos termos de consentimento, em 16/08/2012.

Após concluída, a pesquisa foi apresentada aos trabalhadores no ano de dois mil e quatorze, apesar das dificuldades logísticas para reunir uma equipe de internação.

\section{O exercício da Inteligência Prática em uma enfermaria oncológica}

$\mathrm{Na}$ enfermaria estudada, destacamos duas principais formas de manifestação daquilo que Dejours chamou de Inteligência Prática ou Inteligência Astuciosa. A primeira delas foi no exercício da palavra e da escuta, a segunda, no exercício da produção de conforto, não somente físico, para pacientes e familiares.

Para a compreensão desses resultados julgamos importante destacar, inicialmente, o contexto de grandes mudanças gerenciais que vêm sendo implementadas na administração pública no Brasil, especialmente a partir dos anos 90. No setor saúde, tais mudanças iniciam-se nos hospitais, tendo-se estendido, mais recentemente, para a atenção básica. Hoje, os serviços públicos de saúde encontram-se dominados pela lógica da produtividade, dos indicadores e números. A necessidade de metas, números e indicadores é justificável e justificada, tendo em vista as necessidades dos usuários do Sistema Único de Saúde (SUS) e o imperativo de se garantir universalidade e equidade no acesso aos serviços de saúde, com qualidade e eficiência no uso dos recursos públicos. No entanto, é preciso considerar, como já observamos acima, que o trabalho em saúde possui características que o torna pouco visível, se não totalmente invisível para os métodos de gestão tradicionais 7 . Assim, tais processos, embora centrais para a qualidade do cuidado, não são passíveis de apreensão direta ou mensuração. Isto coloca um problema cada vez mais relevante para a gestão que é a relação dos trabalhadores de saúde com suas organizações e os muitos métodos de gestão que vêm sendo implantados na atualidade, no contexto que Gaulejac ${ }^{8}$ denomina de "quantofrenia aguda".

A demanda por produtividade é crescente e se coloca para todas as hierarquias das organizações públicas de saúde, envolvendo tanto diretores, gerentes, como trabalhadores. As cobranças por números, indicadores e metas quase nunca têm contrapartida na garantia de condições materiais e de pessoal necessários para alcançá-los. Sabemos que não se faz gestão sem avaliação, sem metas e indicadores. A questão é que cada vez mais a lógica produtivista vem tomando o lugar das avaliações qualitativas sobre os processos de trabalho, desvalorizando o lugar da interação humana nos processos de gestão e de produção do cuidado em saúde.

Neste contexto, a pesquisa ${ }^{1}$ detectou um certo grau de desmobilização para o trabalho a partir do relacionamento dos trabalhadores com a gestão. Tal desmobilização se expressava em falas, como Não falo mais nada; Não me manifesto mais, Não dou mais opinião e, até mesmo, - talvez como estratégia defensiva contra seu sofrimento, se manifestava na apatia, descuido, descaso ou indiferença dos trabalhadores para aqueles de quem deveriam cuidar. Condicionando esta situação, a pesquisa apontou, principalmente, uma percepção, pelos trabalhadores, da invisibilidade do esforço por eles empreendido na tarefa de prover o cuidado para pacientes em condições materiais, técnicas e de tempo que consideravam não adequadas ao exercício do cuidado.

Para além das muitas exigências de domínio técnico e de conhecimentos científicos que se colocam para o exercício da prática profissional de enfermagem, essas trabalhadoras e trabalhadores 
são profundamente exigidos no exercício de seu ofício, na medida em que, no trabalho em saúde, se encontram com outros corpos, outras vidas, outras histórias, em um momento de profunda fragilidade, que é o momento da doença e, nesse caso, o momento da internação. Soma-se a isso o fato da enfermagem ser responsável pela continuidade do cuidado. Diante dessas situações, muitas vezes dramáticas, são exigidos em habilidades que não são prioridade em suas trajetórias de formação, tais como lidar com o medo da morte, da perda de um familiar e outras situações profundamente delicadas, principalmente em nossa cultura, que afasta a ideia de finitude, calcada principalmente na potência, no sucesso e na juventude? .

Lidar com essas questões é algo demandado cotidianamente a todos os profissionais de saúde, mas estas questões incidem com maior intensidade sobre a equipe de enfermagem, por que é esta que acaba exercendo um contato mais íntimo com os pacientes, manuseando seus corpos, testemunhando cotidianamente seu sofrimento e, ainda, o que é frequente, tendo que "preparar" seus corpos depois de mortos. Assim, a enfermagem acaba por estabelecer uma relação estreita com esses sujeitos e familiares, dando cabida para a manifestação ou produção de afetos próprios de uma relação tão íntima.

Tais vínculos e situações, com pacientes e familiares, são percebidos, muitas vezes, como assustadores, angustiantes, como eventos que convocam trabalhadoras e trabalhadores a exercerem saberes que vão muito para além de seu saber técnico e científico.

Dejours afirma que é no encontro do trabalhador com seu trabalho que emerge a Inteligência Prática e que este, o trabalho, não é apenas uma "tarefa", mas coloniza a subjetividade: Encontrar soluções, inventar novos caminhos, isso passa por uma transformação de si, profunda. $O$ trabalho não cessa no ateliê, na fábrica ou no hospital. Ele coloniza toda a subjetividade . $^{3}$

Assim, vamos descrever as formas principais como a Inteligência Prática se manifestou no modo como a enfermagem realiza seu trabalho na enfermaria estudada. Diante dos desafios desse contexto, foi pela palavra e por gestos que a equipe de enfermagem que atuava naquele setor, expressava os seus modos de transpor os obstáculos. A equipe não deixava de criar, a despeito de um modo de organização do trabalho que dificultava o debate sobre essas micro criações cotidianas, que resistiam não somente aos obstáculos, mas ao contexto adverso.
Em medicina, assim como em enfermagem, ensinam-se apenas conhecimentos aos estudantes, não se pode ensinar o trabalho propriamente dito. [...] Ocorre com a aprendizagem do profissional de saúde o mesmo que com a criança: não se ensina uma criança a andar, pode-se segurá-la pelas mãos, mas não se explica como tensionar os músculos, mover as articulações, encadear os movimentos. É necessário que ela descubra sozinha e que, como nós, passe à experiência do real...são inúmeras quedas, equimoses até que ela descubra ou invente soluções para recobrar o seu equilíbrio quando cambaleia ${ }^{2}$.

Assim, o exercício de produção de cuidado é um exercício de criação, de deixar emergir a inteligência prática, a métis, que é uma inteligência não racional, que passa pela razão somente $a$ posteriori. Deixar emergir do contato prolongado com o usuário essa inteligência astuciosa:

O conhecimento que eu adquiro no lidar no dia -a-dia, com caso a caso, vai enriquecendo. É como um grão de areia. Vai, vai somando, entendeu? Dentro de mim. A maior parte do que eu sou hoje, eu aprendi lidando frente a frente. (Enfermeira na entrevista individual).

\section{Inteligência Prática como palavra e escuta}

Um dos elementos frequentes nas observações foi o modo como técnicas, técnicos e enfermeiras não só se comunicavam com os pacientes, mas também como estabeleciam com eles uma conexão, por meio da palavra, enquanto executavam - e concebiam de seu modo - os procedimentos prescritos. Percebemos que o ato de escutar e falar podia ser tanto um gesto de acolhimento entre equipe e pacientes, como também, em algumas vezes, tinha função de produção de sentindo, contribuindo para que os pacientes pudessem refletir ou observar sua doença e seu estado por outros ângulos possíveis.

Havia um entendimento geral de que era preciso escutar, que o ato de escutar faz parte do trabalho, que paciente e familiar que não têm sua palavra escutada tendem a gerar problemas mais tarde. Uma enfermeira diz na entrevista individual:

Tento de todas as alternativas possíveis, para diminuir as queixas, o sofrimento, porque paciente e familiar não ouvidos... significa... quase que significa problema para mim. Porque aquilo se avoluma. Entendeu? Não tem como eu ficar escapando disso.

No exercício do cuidado, a equipe de enfermagem costumava preencher as lacunas que fi- 
cavam nas relações entre médicos e pacientes, ajudando na construção de sentidos a respeito do momento vivido por aqueles pacientes, apaziguando angústias:

E atribuições que nós temos é o que a gente faz com os pacientes, né? Banho, ajudar na alimentação, punções, até trabalho também de conversação, que às vezes o paciente só precisa disso. Só da conversação. Às vezes ele pode estar rebelde, você chega lá, conversa com ele, explica. Às vezes é um procedimento que não é explicado a ele. Ele sabe que ele vai fazer uma cirurgia, mas ninguém chega para ele e diz como vai ser a cirurgia [...]. (Enfermeira na entrevista individual).

Na mesma direção, uma técnica faz referência ao papel da palavra, da mediação exercida por ela, durante os momentos de cuidado, na relação entre médico e paciente e na produção de sentido a respeito da doença:

Eu procuro mostrar, sei lá, a coisa boa do momento. Conversar, espairecer. Eles conversarem comigo, começam a falar: 'ah, eu não sei porque eu tô aqui, porque esse problema'. Ai eu falo: Como a senhora começou a observar isso? Aí, começam a me contar: 'começou com uma dor assim e tal. [...] Eu geralmente oriento: 'conversa com seu médico, procura saber, procura entender o que está acontecendo.' (Técnica de enfermagem na entrevista individual).

A técnica exerce essa mediação - com comedimentos em função de seu lugar na hierarquia hospitalar - na medida em que, como ela fala, são muitas pessoas humildes, muitas pessoas humildes que passam por isso, que estão passando por isso e essa humildade dos pacientes, muitas vezes, exige um mediador entre o médico e eles, papel geralmente ocupado por técnicos ou enfermeiras. Estes, talvez pela posição intermediária que ocupam na hierarquia hospitalar e na divisão técnica e social do trabalho em saúde, possam se identificar mais com os pacientes e estar mais abertos, mais disponíveis a exercer tal mediação, mais disponíveis a ouvir e acolher o sentido ${ }^{10}$ no encontro com este outro, o paciente, que deles se aproxima em sua posição de menor poder nas relações assistenciais.

A enfermagem, nesse caso, ocupa o papel de mediação entre a categoria médica, cujo poder e prestígio profissional se encontram no topo da estrutura hospitalar, e o paciente "humilde": aquele que não está compreendendo sua doença e os motivos que o levam a estar ali, mas também aquele para o qual o linguajar médico é ininteligível, aquele que precisa mesmo ser estimulado pela técnica a fazer perguntas para o médico:
Eu não sei se eles se sentem mais à vontade com a gente. Eles veem aquela figura do médico, que pode causar um certo receio. [...] E tem muitos [médicos] que não dão abertura para o paciente conversar. Então [...] eu sempre converso muito e quero saber como é que está tudo acontecendo aí. Aí se abrem mais comigo. [...] eles falam coisas para mim que não falam para o médico e aí eu tenho que acabar direcionando também entendeu? [...] (Técnica na entrevista individual).

A transcrição acima também demonstra a adequação que a técnica faz de seu ritmo de trabalho ao ritmo do paciente e como esse ajuste vai desembocando em uma possibilidade de vínculo entre o paciente e ela, de forma que o paciente possa se sentir à vontade para falar.

Além do explicar, do esclarecer aquilo que o médico não conseguiu esclarecer ou comunicar ao paciente, há também a dimensão do acolhimento:

Às vezes eu chego no leito pra fazer alguma medicação, aí o paciente começa a conversar, eu procuro escutar. Porque às vezes só de você escutar você está ajudando a pessoa, ela tá desabafando. [...] Eu procuro não dar opinião, dar decisões, entendeu? Eu só escuto mesmo. Fico escutando. [...]. (Técnica na entrevista individual).

Uma outra técnica, ao exercer seus atos de cuidado, procura explicar todos os procedimentos para os pacientes, a fim de lhes minimizar a angústia:

Outra técnica de enfermagem observa: [...] vou fazer a medicação [...] eu falo o nome, qual é, explico [...].

Uma técnica revela como seu trabalho de conversação a auxilia na própria realização da "evolução”, isto é, do registro das condições do paciente e do seu bem-estar ao longo do dia:

Mas eu procuro, na hora do banho, aí vou conversando, aí vou perguntando... [...]. Como é que passou a noite, como é que está se alimentando. Já... dali da conversa que eu já vou fazendo minha evolução.... [...] Eu, eu procuro assim, dar uma certa liberdade para eles, entendeu? [...] Deixo eles falarem um pouco, eu fico cuidando, estou fazendo, estou fazendo... [...]. (Técnica de enfermagem na entrevista individual).

Uma enfermeira plantonista fala como compreende seu trabalho e conta, como em suas palavras, desconstrói mitos. Ela começa falando dos efeitos deletérios de pequenas fantasias, na forma de dúvidas que vão crescendo nos pacientes:

Então tento diminuir [...] o grau de sofrimento. Tento estimular para sair daquele quadro de tristeza em que se encontram. E inseguranças. Quanto 
mais dúvida eu esclarecer, eu sei que é melhor. Porque às vezes eles ficam... É uma coisa pequena, mas na cabeça deles, uma dúvida vai crescendo e aquilo às vezes não era tudo aquilo. (Enfermeira na entrevista individual).

A estratégia de silenciar para cuidar ou não falar para não machucar, aparece também como uma forma de manifestação da inteligência prática e verifica-se não somente em discursos que se referem diretamente à morte, mas também às condições de vida em geral.

Uma técnica de enfermagem, que tem uma filha adolescente, revela como - em uma situação em que cuidava de uma adolescente de dezessete anos que fora amputada - consegue driblar, não falar tudo, mas ocultar, em nome do bem-estar da paciente. A menina doente e sua mãe lhe perguntavam se tinha filhos e ela sentia como se não pudesse falar muito sobre sua filha, por ser esta uma menina sadia, enquanto a usuária de quem tratava tinha muitas limitações:

Você sabe ... eu evitava de quando ela perguntava, ou a mãe dela: 'Ah... você tem filho?'. Eu falei: 'Tenho, tenho uma filha também'. Ela disse: 'ah... tem quantos anos?' Eu só respondi a idade. Ai ela me olhava... Mas assim, sabe quando você tenta ocultar falar da sua filha, porque você sabe que a minha filha é uma menina sadia [...]? Uma menina que faz dança, que estuda, vai à escola. E você olhar para aquela menina que está ali, que vê que ela não faz nada disso...Que ela não pode [...].

No entanto, a técnica consegue encontrar uma forma de acesso à menina pela via do humor, podendo promover alguma identificação entre a paciente e sua filha, a princípio tão diferentes em suas situações de doença e saúde. Além disso, o humor também lhe permitiu, a ela, técnica de enfermagem, lidar com os afetos que o processo de identificação com o par mãe-filha doente lhe mobilizavam, já que lhe remetiam à relação com sua filha também adolescente.

Aí teve um dia que eu fui levar ela para o banho, [...], aí a mãe dela falou assim: 'Ih olha só, a enfermeira vai acabar vendo suas coisinhas' $e$ tal. Eu falei: 'Ah, não liga não, porque minha filha fala também que isso aí é a maior Mata Atlântica'. Menina, ela abriu um sorriso daqui até aqui (faz o gesto no rosto, mostrando um sorriso largo). (Técnica na entrevista coletiva).

Dessa forma, o exercício do cuidado se apresenta não só como falar, mas como calar, como retroceder, como recuar, como ocultar e, nesse caso, além de calar, depois poder brincar em meio ao drama.

\section{Inteligência prática como conforto}

Frente à impotência sobre a cura e a morte, técnicos, técnicas e enfermeiras fizeram menção à possibilidade de dar conforto para os pacientes, conforto diante da morte, conforto nos últimos momentos de vida, conforto de fazer o possível dentro de sua impotência diante de temas de tanta intensidade de afetos:

Eu sei que eu não vou poder mudar aquele quadro dele [do paciente], eu não tenho o poder da cura, está além do meu alcance. [...] mas o que eu puder trazer de conforto, de ajuda... Teve uma paciente outro dia que me pediu picolé de limão. Ai já tinha passado o horário de almoço e tudo. Ai eu fui, liguei pra a nutricionista e falei com ela: Josefa, tenta arranjar um picolé de limão pra paciente porque ela já não tá comendo, ela não consegue comer mais nada e ela falou que deu uma vontade tão grande de comer um picolé de limão. Uma coisa tão simples, que se eu que tenho saúde e me der vontade eu vou lá na rua e compro. Ela não tem como fazer isso. [...]. (Técnica de enfermagem na entrevista individual).

Observamos algumas cenas de técnicos, técnicas e enfermeiras negociando com as nutricionistas alimentos não prescritos ou mesmo não recomendados para usuários muito próximos ao fim de vida, alguns muito jovens. Em uma das cenas, uma enfermeira negociou firmemente com a nutricionista também um picolé, para uma usuária de vinte e três anos já com desconforto respiratório. A nutricionista argumentou que só seria possível liberar o picolé caso a enfermeira estivesse presente ao lado da paciente auxiliando, até que a mesma terminasse o picolé, para que não houvesse aspiração para o pulmão.

Nesse episódio se mostrou presente não somente a compreensão de que aquele picolé era mais que um alimento físico, que representava um desejo de vida da paciente, que estava próxima da morte, mas também de que as demandas dos pacientes - embora possam passar por algo que, inicialmente, é aparentemente físico - vão bem para além do biológico; que cabem negociações com outros profissionais para acolher essas demandas - quando o tempo do cuidado permite, frente a tantas demandas diferentes - e que é relevante fazer dos momentos próximos à morte algo que seja positivo para o usuário.

Houve um dia que um familiar veio abordar um técnico, afirmando que a paciente estava desconfortável. O técnico foi ao leito, perguntou o que ela sentia, ao que a paciente respondeu: “(...) 
uma coisa ruim..." Ele trocou a paciente de posição algumas vezes, pediu que ela sentasse, que mudasse de posição, ofereceu uma água, e continuou perguntando como ela se sentia, até que ela respondeu que estava melhor. Ao retornar para o posto, a pesquisadora do campo perguntou o que ele havia feito e que como havia compreendido aquele episódio, ao que me respondeu: A gente sabe que o mal-estar que ela está sentindo não é só físico, mas a gente vai lá, tenta dar um conforto, tenta dar uma atenção e aí pode ser que ela se sinta melhor um pouco...

Portanto, o saber sobre as expressões de mal -estar é algo muito mais refinado do que está contido na formação técnica de enfermagem e passa por este encontro do corpo a corpo com o trabalho.

As formas de dar o conforto entre técnicas, técnicos e enfermeiras são diversificadas, como nas falas abaixo, em que se apresenta a questão da escuta, do avançar e recuar, conforme a necessidade dos usuários, que remetem à produção de cuidado como um savoir-faire discreto, tal como nos descreve Pascale Molinier":

Um trabalho atencioso, quando bem feito, não se vê! Seu sucesso depende em grade parte de sua discrição, ou seja, da supressão de seus rastros. [...] $O$ beneficiário não sabe o quanto custou a quem executou o serviço, tanto mais porque essa pessoa antecipou-se às suas necessidades antes mesmo que fossem expressas.

Uma técnica menciona como faz para lidar com os excrementos dos usuários, mencionando o cuidado e o conforto também como este trabatho sujo, que ninguém faz e como ela lida, no relacionamento com o usuário, com essa intimidade, esse contato com os humores e excrementos de modo a evitar constranger e violentar o usuário:

Porque eu sei que aquele paciente não é aquele, aquele...não são aqueles excrementos. Que tudo aquilo é uma coisa natural. Que está em mim. Então, eu sempre me coloco, procuro me colocar no lugar daquele paciente. Como eu gostaria de ser manipulada se eu estivesse naquela situação? [...] Então, na medida do possivel, sempre procurar respeitar o corpo. [...] Você se preservou, se resguardou durante tantos anos e de repente você tem que ficar exposta o tempo todo para uma pessoa que você nunca viu $[. .$.$] porque você está precisando. Então,$ eu procuro manipular com meu toque. Na hora da higienização, de lidar com essas eliminações, esses excrementos e tal de uma forma mais natural possivel, porque eu fico imaginando a minha expressão ao ver alguém recolhendo o que eu eliminei com uma certa ojeriza, né? [...] A gente registra os odo- res, não tem como não-registrar. Mas eu procuro ser o mais natural possivel. (Técnica na entrevista individual).

Nesse trecho da fala da técnica - que condensa a fala de muitas trabalhadoras e trabalhadores da enfermagem entrevistados na pesquisa - o cuidado aparece nas suas cinco dimensões enunciadas por Pascale Molinier": o cuidado como gentelness (gentileza), como savoir-faire discreto, como trabalho sujo, como trabalho inestimável e como narrativa ética.

A técnica compreende a fragilidade do usuário não somente pela doença em si e seus desdobramentos no corpo físico, mas pela sua falta de autonomia, pelo fato de ele ter que se submeter a ter seus excrementos limpos por um estranho. A partir dessa interpretação da condição do usuário, a técnica usa de suas habilidades, inclusive de seu corpo, de sua expressão facial e de suas emoções para manter o sentimento de dignidade do usuário tanto quanto lhe é possível.

O cuidado aparece nesse trecho de fala também como savoir-faire discreto, na medida em que tomar cuidado com suas expressões e procurar ser o mais natural possivel, apesar de registrar os odores (com seu sentido olfativo), ao limpar os excrementos de um usuário é uma atitude discreta, não percebida por quem está de fora e que se antecipa à expressão da necessidade do usuário.

Essa atitude de cuidado aparece também em sua dimensão de trabalho sujo, na medida em que limpar os excrementos de um outro é algo, no senso comum, considerado repugnante, que se evita fazer e é delegado a pessoa em posições sócio-profissionais consideradas hierarquicamente inferiores.

Nesse trecho da fala da técnica, o cuidado aparece também como trabalho inestimável, na medida em que é imprescindível, não passível de prescrição e, ao mesmo, não mensurável:

O trabalho inestimável não é mensurável, especialmente através de métodos de gestão: como medir um sorriso ou uma presença? Seu valor não tem preço, o que torna altamente complexa a questão de sua remuneração: por que aquilo que mais valor tem é o que menos se remunera?4.

Finalmente, podemos afirmar também que o cuidado aparece aqui como narrativa ética, na medida em que sai de estereótipos de bondade ou idealização dos cuidados para algo que se dá na concretude da relação, que aparece como uma atitude ética entre quem cuida e quem é cuidado, para além de qualquer bondade, pena ou benevolência. 


\section{Considerações finais}

Observamos que o exercício da inteligência prática pelos trabalhadores de enfermagem na enfermaria oncológica pesquisada se expressam nas formas de falar, escutar, calar e produzir conforto por parte da equipe de enfermagem. Tais formas de inteligência prática se interpenetram e não são passíveis de captura por números, indicadores e métodos de avaliação do desempenho. São invisíveis para instrumentos que não passem pela palavra dos trabalhadores.

Quando esse saber-fazer dos trabalhadores da atenção tende a ficar na invisibilidade, importantes prejuízos para a qualidade do cuidado se colocam. Um deles é o aumento da distância entre os trabalhadores da atenção e os trabalhadores da gestão. Outra é o aumento do sofrimento do trabalhador e sua desmobilização para com o trabalho.

O reconhecimento de que o trabalho humano não se reduz aos resultados imediatamente materiais ou quantificáveis do mesmo, compreendendo uma dimensão muito mais ampla e intangível, dificilmente visível ou passível de apreensão por métodos tradicionais de avaliação, é uma compreensão compartilhada entre a Psicodinâmica do Trabalho ${ }^{11,12} \mathrm{e}$ as demais abordagens que são consideradas "clínicas do trabalho"13,14, como a Clínica da Atividade ${ }^{15,16}$ e a Ergologia ${ }^{17}$. Para essas perspectivas, o trabalho exigirá sempre a contribuição singular e coletiva dos trabalhadores. Mais do que um reencontro e troca com outros, exigirá um fazer com outros, sobre um objeto comum, um saber-fazer que se situa entre a repetição e a criação, entre o feito e o por criar $^{14}$, e por isso campo privilegiado de mediação entre a singularidade do trabalhador e o social.

Nesta perspectiva, torna-se imperativo a criação de espaços coletivos nas organizações de saúde em que gestores e trabalhadores possam expressar e dialogar sobre tais questões, validando-se socialmente esse saber-fazer e essas experiências dos trabalhadores e, portanto, convertendo a inteligência prática em sabedoria prática, esta última, de caráter coletivo. Por fim, cabe destacar que tirar da invisibilidade essas dimensões intangíveis do cuidado pode representar uma importante oportunidade para se rever o modo de organização do trabalho, as rotinas, as práticas, fortalecendo seu potencial de produção de cuidado.

\section{Colaboradores}

MLG Fonseca participou da concepção do estudo, da realização da pesquisa, da análise dos dados, da redação e revisão crítica do manuscrito. MC Sá participou da concepção do estudo, da análise dos dados, da redação e revisão crítica do manuscrito. 


\section{Referências}

1. Fonseca MLG. Da prescrição à criação: inteligência prática, produção de cuidado e invisibilidade no trabalho de uma equipe de enfermagem em oncologia [tese]. Rio de Janeiro: Escola Nacional de Saúde Pública; 2014.

2. Dejours C. Trabalho Vivo. Tomo I e Tomo 2. Brasília: Editora Paralelo 15; 2012.

3. Lancman S, Sznelzar LI, organizadores. Chistophe Dejours: Da Psicopatologia à Psicodinâmica do Trabalho. $2^{\text {a }}$ ed. Rio de Janeiro, Brasília: Ed. Fiocruz, Ed. Paralelo $15 ; 2008$.

4. Molinier P. Ética e trabalho do Care. In: Hirata H, Guimarães NA, organizadores. Cuidado e cuidadoras: as várias faces do trabalho do Care. São Paulo: Editora Atlas; 2012. p. 30-43.

5. Lévy A. Ciências Clínicas e Organizações Sociais. Belo Horizonte: Editora Autêntica/Fumec; 2001.

6. Giust AC. Entrevista. In: Barus-Michel J, Enriquez E, Levy A, organizadores. Dicionário de Psicossociologia. Lisboa: Climepsi Editores; 2005. p. 262-269.

7. Fonseca MLG, Sá MC. A Insustentável Leveza do Trabalho em Saúde: excessos e invisibilidade no trabalho da enfermagem em oncologia. Saúde debate [online]. 2015; 39(n. spe):298-306.

8. Gaulejac V. A Gestão como Doença Social: ideologia, poder gerencialista e fragmentação social. Rio de Janeiro: Editora Idéias e Letras; 2007.

9. Kovács MJ. Morte e Desenvolvimento Humano. São Paulo: Casa do Psicólogo; 1992.

10. Barus-Michel J. Clínica e Sentido. In: Barus-Michel J, Enriquez E, Lévy A, organizadores. Dicionário de Psicossociologia. Lisboa: Climepsi Editores; 2005. p. 242-250.

11. Dejours C. Intelligence pratique et sagesse pratique: deux dimensions méconnues du travail réel. Éducation Permanente 1993; 116:47-70.
12. Molinier P. Qu'est-ce que le care? Paris: Payot, Collection Petite Bibliothèque; 2009.

13. Bendassoli PF, Soboll LAP organizadores. Clínicas do Trabalho: novas perspectivas para a compreensão do trabalho na atualidade. São Paulo: Ed. Atlas; 2011.

14. Lhulier D. Cliniques du Travail. Nouvelle revue de psychosociologie 2006; 1:179-193.

15. Clot Y. Clínica do Trabalho e Clínica da Atividade. In: Bendassoli PF, Soboll LAP, organizadores. Clínicas do Trabalho: novas perspectivas para a compreensão do trabalho na atualidade. São Paulo: Ed. Atlas; 2011. p. 71-83.

16. Osório da Silva C. Pesquisa e Intervenção em Clínica da Atividade: a análise do trabalho em movimento. In: Bendassoli PF, Soboll LAP, organizadores. Métodos de Pesquisa e Intervenção em Psicologia do Trabalho. São Paulo: Editora Atlas; 2014. p. 81-99.

17. Schwartz Y. Manifesto por um Ergoengajamento. In: Bendassoli PF, Soboll LAP, organizadores. Clínicas do Trabalho: novas perspectivas para a compreensão do trabalho na atualidade. São Paulo: Ed. Atlas; 2011. p.132-166.

Artigo apresentado em 07/04/2019

Aprovado em 20/08/2019

Versão final apresentada em 04/10/2019 